\title{
KLENTENG KWANG SING BIO DI KELURAHAN KARANGSARI, KECAMATAN TUBAN, KABUPATEN TUBAN, JAWA TIMUR (SEJARAH, STRUKTUR DAN FUNGSI SERTA POTENSINYA SEBAGAI SUMBER BELAJAR SEJARAH DI SMA)
}

Thobi'atul Husna

\author{
Alumni Jurusan Pendidikan Sejarah Universitas Pendidikan Ganesha \\ thobiatulhusna2015@gmail.com
}

\begin{abstract}
ABSTRAK
Tujuan penelitian ini adalah untuk mengetahui (1)Sejarah berdirinya Klenteng Kwang Sing BioTuban (2) stuktur dan fungsi dari bangunan Klenteng Kwang Sing Bio,(3)aspek-aspek yang dapat digunakan dari bangunan Klenteng Kwang Sing Bio sebagai sumber belajar sejarah di SMA. Jenis penelitian ini menggunakan pendekatan kualitatif, dengan tahap-tahap: (1)lokasi penelitian di Klenteng Kwang Sing Bio di kelurahan karangsari, kecamatan Tuban, kabupaten Tuban,Jawa Timur (2)Metode penentuan informan menggunakan Purposive Sampling, dikembangkan dengan Snow Ball (3)Metode pengumpulan datamelalui observasi, wawancara, dan studi pustaka (4)validasi data menggunkan trianggulasi data dan trianggulasi metode),(5)analisis data menggunakan analisis interaksi. Hasil penelitian menunjukkan bahwa,(1)sejarah pendirian Klenteng kwang sing bio ini dimulai dari periode awal pada tahun 1742-1970 dan mengalami pengembangan bangunan dari periode tahun 1970 hingga-sekarang(2)Struktur klenteng Kwang Sing Bioterdiri dari beberapa bagian, yaitu bangunan utama, bangunan tengah, bangunan barat, dan bangunan belakang,klenteng Kwang Sing Bio memiiliki 5 fungsi yaitu fungsi religi, sosia, ekonomi, destinasi wisata dan pendidikan(3)Klenteng Kwang Sing Bio berpotensi sebagai sumber belajar sejarah di SMA di kelas X dan XI berdasarkan kurikulum 2013, adapun aspek-aspek yang dapat digunakan yaitu: aspek sejarah, aspek bangunan, dan aspek kerukunan antar umat beragama.
\end{abstract}

Kata Kunci: klenteng, struktur, fungsi, sumber belajar

\begin{abstract}
The purpose of this research is to know (1) History of Kwang Sing Bio Tuban stand (2) structure and function of Kwang Sing Bio temple building, (3) aspects that can be used from Klagenese Kwang Sing Bio building as a source of history learning in SMA. This research used qualitative approach, with stages: (1) research location at Klenteng Kwang Sing Bio in Karangsari village, Tuban sub-district, Tuban district, East Java (2) Informant determination method using Purposive Sampling, developed with Snow Ball (3) ) Data collection method through observation, interview, and literature study (4) data validation using triangulation data and triangulation method), (5) data analysis using interaction analysis. The result of the research shows that (1) the history of the establishment of Klagoeng kwang sing bio started from the early period in 1742-1970 and experienced the development of the building from the period of 1970 to the present (2) The structure of Kwang Sing Bio temple consists of several parts, The main building, the central building, the western building, and the rear building, the Kwang Sing Bio temple has 5 functions, namely religious function, socio-economic, tourism and education destination (3) Kwang Sing Bio Klenteng has the potential to learn history in high school in class X and XI Based on the curriculum 2013, as for the aspects that can be used are: aspects of history, aspects of the building, and aspects of harmony between religious communities.
\end{abstract}

Keywords: pagoda, structure, function, learning resource 


\section{PENDAHULUAN}

Indonesia merupakan negara multikultur yang memiliki begitu banyak ragam kebudayaan. Indonesia terdiri dari berbagai macam etnis, ras, suku bangsa, budaya, dan agama yang semakin menguatkan sekaligus meramaikan keanekaragaman tersebut. Di Indonesia terdapat enam agama yang resmi diakui oleh negara, di antaranya: Islam, Kristen Katolik, Kristen Protestan, Hindu, Budha dan Konghucu. Keberagaman agama dapat ditunjukkan pada bangunan-bangunan suci yang ada di Indonesia. Salah satu bangunan suci tersebut berupa Klenteng yang berada di Jalan R.E. Martadinata, Desa Karangsari, Kecamatan Tuban, Kabupaten Tuban, Jawa Timur.

Berdasarkan data Badan Pusat Statistik Kabupaten Tuban tahun 2014, jumlah penduduk beragama Budha dan Konghucu jika digabungkan hanya berjumlah 591 jiwa, dibandingkan dengan penduduk beragama Islam yang berjumlah $1,216,949$ jiwa (https://tubankab.bps.go.id/linkTabelStatis/ view/id/214, diakses tanggal 9 maret 2017).Fakta ini menarik karena di tengah kawasan yang mayoritas penduduknya beragama Islam terdapat bangunan Klenteng yang sangat besar.Hal ini mengindikasikan bahwa dahulu saat klenteng tersebut dibangun umat Budha atau Konghucu jumlahnya besar atau pengaruhnya kuat.Untuk membuktikan hal tersebut, maka harus ditelusuri sejarah pendirian klenteng tersebut, dan belum banyak yang tahu Oleh karena itu, penulis tertarik untuk meneliti lebih lanjut tentang sejarah berdirinya Klenteng Kwang Sing Bio Tuban.

Bangunan suci apapun pasti memiliki beberapa struktur dan fungsi. Klenteng Kwang Sing Bio merupakan klenteng terbesar di Jawa Timur dengan luas 4 hektar.Klenteng ini berada di depan pantai dengan berjarak sekitar kurang lebih $10 \mathrm{M}$ tanpa adanya penghalang, seolah-olah memberikan kesan yang sangat istimewa. Selain itu patung kepiting raksasa yang terdapat di atas pintu gerbang dianggap sebagai keunikan tersendiri, sehingga orang akan merasa aneh jika melihatnya. Oleh karena itu, hal ini menarik untuk diteliti lebih lanjut tentang bagaimana struktur dan fungsi dari bangunan Klenteng Kwang Sing Bio Tuban, Jawa Timur.

Selain sebagai tempat ibadah, bangunan Klenteng Kwang Sing Bio juga dapat dipergunakan sebagai sumber belajar bagi siswa-siswi yang ada di sekitar Klenteng tersebut. Pentingnya bangunan Klenteng Kwang Sing Bio Tuban sebagai sumber belajar sejarah baik di kelas $X$ dan kelas XI. Mengingat selama ini yang penulis amati, bahwa banguan tersebut hanya diperuntukan bagi para wisatawan yang ingin menikmati keindahan dan kemegahannya bangunan klenteng, sedangkan dalam proses pembelajaran belum dimanfaatkan secara maksimal. Keberadaan kelnteng Kwang Sing Bio tidak hanya sebagai tempat rekreasi saja tetapi juga dapat digunakan sebagai sumber belajar sejarah siswa dalam rangka membina kesadaran sejarah mereka.Apresasai siswa dan guru yang rendah dalam memanfaatkan bangunan klenteng Kwang Sing Bio Tuban ini sebagai media edukasi menyebabkan keberadaan bangunan klenteng Kwang Sing Bio Tuban belum dimanfaatkan sebagai sumber belajar sejarah.

Berdasarkan paparan di atas artikel ini membahas tentang (1) Sejarah pendirian klenteng Kwang Sing Bio, di kelurahan Karangsari, Kecamatan Tuban, Kabupaten Tuban, Jawa Timur, (2) struktur dan fungsi bangunan Klenteng Kwang Sing Bio di Kelurahan Karangsari, Kecamatan Tuban, 
Kabupaten Tuban, Jawa Timur, (3) 1.2.3

Aspek-aspek apa saja dari Klenteng Kwang Sing Bio Tuban yang dapat digunakan sebagai sumber belajar sejarah di SMA

\section{METODE PENELITIAN}

\section{Jenis Penelitian}

Jenis penelitian yang digunakan dalam penyusunan penelitian ini ialah jenis penelitian yang menggunakan pendekatan kualitatif yang bersifat induktif, permasalahan-permasalahan tersebut muncul dari data, yang dihimpun dengan pengamatan yang seksama, mencakup deskripsi dalamm konteks yang mendetail disertai catatan-catatan dari hasil wawancara yang mendalam, serta hasil analisis dokumen dan catatan-catatan penting lainnya (Sukmandinata, 2009:60).

\section{Lokasi Penelitian}

Penelitian ini dilaksanakan di Klenteng Kwang Sing Bio, Kelurahan Karangsari, Kecamatan Tuban, Kabupaten Tuban, Jawa Timur. Lokasi ini diambil karena klenteng ini adalah klenteng terbesar di Jawa Timur, dan ada komunitas Tionghoa yang hidup harmonis dengan etnis mayoritas yaitu etnis jawa yang beragama Islam.Berdasarkan pertimbangan itu penulis tertarik untuk meneliti lokasi ini.

\section{Metode Penentuan Informan}

Dalam hal ini untuk memperoleh data yang akurat dan relevan dengan kajian penelitian, maka peneliti menggunakan teknik "Purposive Sampling" (sampel bertujuan).yaitu Purposive Sampling artinya tidak semua orang dipilih untuk menjadi informan melainkan hanya orang-orang tertentu yang mengetahui dan mengerti tentang masalah yang akan diteliti. Orangorang tersebut dipilih berdasarkan berbagai pertimbangan, seperti tingkat keahlian, tingkat hubungan sosial, maupun yang bersifat intelektual dan dikembangkan dengan menggunakan teknik Snow Ball.
Informan kunci yang di maksud peneliti yaitu Gunawan Putra Wirawan (50 tahun) selaku ketua umum Klenteng Kwang Sing Bio, kemudian dari beliau didapatkan informan lainnya yaitu Liu kok liong selaku wakil ketua umum klenteng, Tan Ai Kok bendahara umum klenteng, Nurdin Iskandar skretariatan, Siti Istianah guru sejarah MA Ashomadiyah. para pedagang,dan para pengunjung klenteng.

\section{Metode Pengumpulan Data}

Dalam pengumpulan data peneliti menggunakan beberapa metode pengumpulan data diantaranya:

(1) Teknik Observasi

Obersvasi yang dilakukan peneliti langsung mengarah kepada tempat penelitian yaitu Klenteng Kwang Sing Bio Tuban. Untuk memperoleh data yang relevan maka, peneliti terjun langsung ke lapangan degan melihat kemudian mengabadikannya dengan kamera digital, mengamatinya serta menghimpun data darinya (Suwartono, 2014: 42). Yang diobservasi dalam penelitian ini tentang sejarah pendirian klenteng kwaang Sing Bio, struktur dan fungsi klenteng, dan aspek-aspek apa saja yang dapat dijadikan sebagai sumber belajar sejarah di SMA.

Alat yang digunakan dalam observasi berupa kamera digital dan buku catatan untuk merekam atau mengambil gambar dan mencatat halhal yang dibutuhkan dalam penelitian ini.

(2) Wawancara

Pengumpulan data yang dilakukan oleh peneliti menggunakan teknik wawancara langsung yang bersifat terbuka dengan terbuka, agar proses wawancara lebih leluasa dan lebih terarah dengan menggunakan pedoman wawancara, namun tidak menutup kemungkinan dilakukan proses wawancara secara bebas tanpa adanya 
pedoman wawancara. Wawancara dalam penelitian ini dilakukan kepada ketua umum klenteng, wakil ketua umum klenteng, penguru, bendahara klenteng, para pedagang, pengunjung dan guru sejarah di MA Ash Shomadiyah.

(3) Studi Dokumen

Pengumpulan data dengan menggunakan studi dokumen yaitu dengan membaca buku-buku referensi, jurnal-jurnal, dan mengumpulkan dokumen-dokumen penting berupa monografi desa, arsip administrasi klenteng dan foto-foto mengenai Klenteng Kwang Sing Bio Tuban.

\section{Validasi Data}

Dalam validasi ini, peneliti menggunakan dua teknik triangulasi, yaitu triangulasi data (triangulasi sumber data) dan triangulasi metode.

(1) Trianggulasi Data

Triangulasi data atau triangulasi sumber yaitu menghimpun data dari sumber berlainan perspektif (Suwartono,2014:77). Triangulasi data atau sumber meliputi sumber lisan dan sumber tertulis Dalam pengumpulan data, peneliti menggunakan multi sumber data. Misalnya data tentang sejarah Klenteng Kwang Sing Bio, struktur dan fungsinya Klenteng, dan potensinya sebagai sumber belajar sejarah.

(2) Trianggulasi metode

Triangulasi metode yaitu mengumpulkan data yang sejenis tetapi dengan teknik atau metode pengupulan data yang berbeda. Misalnya, menggabungkan catatan lapangan hasil pengamatan dan naskah hasil wawancara (Suwartono, 2014: 76). Dalam hal ini metode pengumpulan data yang dilakukan peneliti yaitu, melalui observasi, wawancara mendalam serta studi dokumen.

\section{Analisis Data}

Analisis data yang digunakan peneliti pada penelitian ini adalah model analisis interaksi.Langkah pertama yang dilakukan yaitu pengumpulan data dan menganalisisnya. Data-data dikelompokkan berdasarkan jenisnya, kemudian dilakukan reduksi data untuk menyeleksi, memfokuskan, dan menyempurnakan data yang dianggap masih kasar, setelah itu diambil data yang paling llengkap dan pokok, Setelah itu, melakukan sajian data dengan tetap mengkomparasikan reduksi data yang dikelompokkan menurut tema dan masalahnya. Selanjutnya dilakukan penarikan simpulan. Jika di rasa kurang mantab dapat dilakukan ulang dengan narasumber lain yang informasia lebih lengkap dengan berdasarkan lagkahlangkah tersebut di atas.

\section{HASIL DAN PEMBAHASAN}

\section{Sejarah Pendirian Klenteng Kwang Sing \\ Bio}

Sejarah pendirian klenteng Kwang Sing Bio dapat di telusuri berdasarkan dua periode, yaitu sebagai berikut:

\section{Periode Awal Pendirian Klenteng Kwang Sing Bio (1742-1970 M)}

Sejarah migrasi orang-orang Tionghoa ke Indonesia terjadi jauh sebelum kedatangan Belanda yang menjajah kepulauan yang kemudian disebut Hindia. Beberapa catatan menunjukkan hal ini terjadi sebelum abad ke-5. Sebagian besar dari mereka datang untuk melakukan perdagangan dengan orang-orang pribumi. Mereka kemudian menikah dengan warga asli lalu menetap dan tinggal sebagai warga Negara Indonesia (Wang Xiang Jun, 2010: 7). Para migran secara meluas berintegrasi dengan penduduk setempat, sehingga 
sekarang orang Tionghoa-Jawa sebagian besar tidak bisa berbahasa Mandarin.

Orang-orang Tionghoa adalah mitra dagang bagi orang Belanda, tepatnya semenjak masa Kompeni Hindia Timur (VOC), dan mereka tidak pernah kehilangan posisi perantara ini, namun bukan berarti hubungan tersebut selalu mulus. Pada kenyataannya, pembantaian massal atas orang-orang Tionghoa di Batavia pada tanggal 9 Oktober 1740, yang mana memaksa warga Tionghoa untuk mencari tempat yang lebih aman.Di mana, kaum kolonial Belanda melakukan pembantaian habis-habisan terhadap warga Tionghoa, yang menelan korban sekitar 10.000 jiwa. Mereka membunuh tanpa mengenal ampun dan kebiadabannya tidak pandang bulu, karena semua warga Tionghoa di bunuh, mulai usia balita sampai usia lanjut. Bahkan, warga Tionghoa yang sakit pun tak luput dari kebiadaban Belanda, baik laki-laki maupun perempuan (Yoes, 2008:45) peristiwa ini dikenal sebagai De Chineezen Grootemoord dan mayatnya mereka hanyutkan ke sungai dan memerahkan sungai yang kemudian dikenal dengan Muara Angke atau sungai merah Jakarta. Akibatnya banyak orangorang Tionghoa yang melarikan diri terutama dari daerah yang berdekatan dengan Batavia (Cirebo, Semarang, Lasem dan sebagainya) menuju ke arah timur, termasuk warga Tionghoa yang di Tambakbayan (sekarang menjadi Tambakboyo) (wawancara bapak Aliong, 2 Juni 2017, pukul. 10:10 WIB).

Di antara para pengungsi yang berasal dari Tambakboyo (wilayah Tuban bagian barat $\pm 30 \mathrm{Km}$ ke arah barat kota Tuban) tersebut, terdapat satu keluarga keturunan Tionghoa yang ikut memindahkan tempat pemujaan berukuran kecil milik mereka ke arah Timur, namun perahu yang ditempatinya tersebut hanya berputar-putar dan tidak bisa berjalan ke arah timur dikaranakan terkena putaran angin yang mana angin tersebut sering terjadi di wilayah Tuban, yang kemudian membuat para pengemudi bingung. Sehingga, mereka berinsiatif untuk melakukan ritual pue, yaitu ritual yang dilakukan dengan cara melempar sepasang "pue" untuk dapat mengetahui kongco (patung yang dianggap manifestasi roh yang dituakan dalam klenteng) apakah roh Kong Co Kwang Sing Tee Koen (tokoh pangglima perang di Cina klasik) ingin menetap di Tuban. Apabila, pue yang dilempar terbuka dua-duanya maka harus diulang, dan jika pue tertutup dua-duanya berarti tidak setuju, tetapi pue terbuka dan tertutup berati pue disetujui. Akhirnya, setelah beberapa kali mereka melempar pue hasilnya adalah terbuka dan tertutup, hal ini berarti Kong Co Kwang Sing Tee Koen setuju untuk menetap di Tuban

Setelah melakukan ritual pelemparan pue dengan hasil persetujuan dari Kong Co Kwang Sing Tee Koen untuk menetap, maka padtahun 1742 M yaitu sekitar tahun 275 tahun yang lalu klentenng Kwang Sing Bio tersebut didirikan.Perkembangan Klenteng Kwang Sing Bio banyak menemukan rintangan pada tahun 1967, ditambah dengan akibat adanya peritiwa G-30 S pada tahun 1965 , yang mana sangat riskan untuk dapat membangun Klenteng Kwang Sing Bio, karena pada saat itu muncullah permasalahan yang menyangkut ras, sehingga menyebabkan adanya peraturan yang intinya adalah segala sesuatu yang ber-etnis Cina tidak boleh melakukan perbaikan, melakukan pembangunan, dan segala sesuatu yang bernuansa Cina dilarang. Akan tetapi hal ini tidak menyurutkan pihak pengurus ataupun orang-orang Tionghoa di Kota Tuban untuk memperbaiki klenteng secara diam-diam, karena mereka tidak ingin tempat ibadah mereka mengalami kehancuran.Pihak 
pengurus pernah mencoba untuk meminta izin dari pihak pemerintah untuk memperbaiki namun, hal itu ditolak karena adanya kebijakan pemerintah pada saat itu.Dan hal ini juga yang akhirnya menyebabkan pada tahun 1967 sebutan klenteng dihilangkan diganti dengan sebutan Tempat Ibadah Tri Dharma.Oleh sebab itu, Klenteng Kwang Sing Bio juga dikenal dengan sebutan Tempat Ibadah Tri Dharma. Mewujudkan bahwa Klenteng Kwang Sing Bio merupakan Tempat Ibaddah Tri Dharma adalah dengan adanya ruangan yang disebut Tri-Nabi yaitu perpaduan dari bentuk ajaran Tri Dharma (Buddha, Taoisme, dan Kong $\mathrm{Hu} \mathrm{Cu}$ ).

\section{Periode Pembangunan Klenteng Kwang Sing Bio (1970 M-Sekarang)}

Berdasarkan perkembangan selanjutnya klenteng Kwang Sing Bio ini secara bertahab mengalami renovasi pertambahan bangunan gedung yang mana perkembangan dimulai dari pembuatan lambang kepiting yang dimulai sekitar tahun 1970 M. Pembuatan lambang kepiting tersebut berjalan lancar meskipun tidak bisa cepat karena pada tahun-tahun tersebut banyak terjadi konflik yang menyangkut ras dan mereka melakukan pembangunan tersebut secara diam-diam, agar tempat ibadah mereka tidak mendapat masalah yang mengakibatkan penghancuran. Hal ini berlangsung cukup lama hingga akhirnya pada masa pemerintahan Abdurrahman Wahid (Gus Dur) pada tahun 2000 semua aturan yang tadinya rasialis dihapus oleh pemerintah. Hal ini berdampak sangat positif bagi pembangunan dan kebebasan berbudaya bagi masyarakat keturunan Tonghoa di negara Indonesia.

Dari tahun 1970-2000, yang sebelumnya hanya bangunan bagian depan yaitu altar dewa utama Klenteng Kwang Sing Bio namun seiring berjalannya waktu dengan banyakanya para donatur yang saling berdatangan untuk menyumbangkan sedikit hartanya demi pembangunan Klenteng dan juga karena perubahan nama dari Klenteng menjadi Tri Dharma pada tahun 1967 oleh pemerintah mengakibatkan klenteng Kwang Sing Bio diperuntukan untuk tiga agama yang mana sangat diperlukan tempat ibadah yang dapat mewadahi ketiga agama tesebut. Maka dari itu, pihak pengurus mulai membagun altar Tri-Nabi yang mana di dalam altar tersebut terdapat tiga patung yang disembah oleh penganut Tri Dharma yaitu Budha Sakyamuni (Budha), Thay Siang Loo Kum (Tao), dan Nabi Kong Tjoe (Kong $\mathrm{Hu} \mathrm{Cu}$ ). Dilanjutkan. Karena, banyaknya para pengunjung yang berdatangan dan banyak dari para pengunjung tersebut yang menyumbang untuk pengembangan bangunan maka, pada tahun 2003 mulai di bangun penginapan berlantai 4 , ruang aula, tepat parkir, dapur umum, panggung pertunjukan, da kios-kios yang diperuntukan bagi umat Tri Dharma kurang mampu, dan bangunan-bangunan yang lainnya.

\section{Struktur dan Fungsi Klenteng Kwang Sing Bio}

Fungsi klenteng Kwang Sing Bio secara umum adalah sebagai tempat ibadah bagi umat Tri Dharmaakan tetapi selain itu juga memiliki fungsi lain seperti fungsi sosial, fungsi ekonomi, fungsi kebudayaan, fungsi destinasi wisata, dan fungsi pendidikan. Sedangkan secara khusus dapat dilihat berdasarkan struktur bangunan yang mana memiliki fungsinya masing-masing.

Struktur dari bangunan Klenteng Kwang Sing Bio ini tidak memiliki makna religi atau filosofi di balik pembagian tersebut, tidak sebagaimana konsep struktur pura di Bali yang dibagi atas tiga halaman (Tri Mandala) yaitu, halaman depan (jaba sisi), halaman tengah (jaba tengah), dan halaman dalam (jeroan). Di dalam Klenteng Kwang Sing Bioterdapat beberapa bagian bangunan inti baik bersifat sakral maupun tidak yaitu 
${ }^{(1)}$ bangunan utama yang terdiri dari komplek altar dewa utama, altar Tri Nabi, yang berfungsi untuk temapt ibadah bagi umat Tri Dharma, dan bangunan 8 dewa yang berfungsi sebagai tempat penyimpanan alat-alat untuk persembahyangan ${ }^{(2)}$ Bangunan tengah yang terdiri dari ruang kebaktian umat budha, ruang kebaktian konghucu dan tao (Litang), dan aula, (3) Bangunan barat yang mana merupakan bangunan yang dipergunakan untuk tempat penjualan aksesoris, ${ }^{(4)}$ bangunan dapur, merupakan bangunan yang berada di sebelah tempat penjual aksesoris yang bangunan ini difungsikan sebagai tempat makan bagi para pengunjung dan makanan tersebut gratis. $\left({ }^{5}\right)$ bangunan belakang yang terdiri dari bangunan 4 lain untuk istirahat para pengunjung, taman dan panggung pertunjukan, dan tempat parkir. Selain yang disebutkan tersebut terdapat juga tempattempat yang terdapat di dalam klenteng kwang sing bio yang juga menarik yaitu Kiemloa, tempat penyimpanan wayang potehi, tempat penjualan Hio, tempat pembacaan Jam $\mathrm{Si}$, dan ruang les bahasa mandarin.

\section{Klenteng Kwang Sing Bio sebagai Sumber Belajar Sejarah di SMA}

Selain sebagai tempat ibadah, bangunan klenteng Kwang Sing Bio juga memiliki potensi yang dapat di jadikan sebagai sumber belajar, khususnya belajr sejarah di SMA yang ada di sekitar Klenteng Kwang Sing Bio, terutama MA Ash Shomadiyah. Potensi klenteng Kwang Sing Bio dapat di lihat pada aspek-aspek yang berada di dalam Klenteng Kwang Sing Bio, akan tetapi potensi tersebut sepenuhnya belum di manfaatkan sebagai sumber sejarah di SMA, terkhusus oleh MA Ashomaddiyah yang belum memanfaatkan kleteng Kwang Sing Bio sebagai sumber belajar khususnya sumber belajar sejarah. aspek-aspek penting dari Klenteng Kwang Sing Bio serta alasan belum dimanfaatkannyaa bangunan Klenteng Kwang Sing Bio sebagai sumber belajar sejarah di SMA adalah sebagai berikut.

\section{Aspek-aspek Penting Klenteng Kwang Sing Bio sebagai Sumber Belajar Sejarah di SMA}

Klenteng Kwang Sing Bio merupakan sebuah Klenteng yang memiliki nilai kesejarahan yang penting dalam kontek perjalanan orang-orang Tionghoa yang ada di Kabupaten Tuban. Pada dasarnya masyarakat mengetahui fungsi klenteng Kwang Sing Bio hanya sebagai tempat ibadah bagi warga Tionghoa, sekaligus salah satu icon tujuan wisata bagi masyarakat Tuban maupun luar Tuban yang bertujuan untuk menikmati keindahan dan kemegahan dari klenteng Kwang Sing Bio. Namun, jika ditelusuri lebih lanjut bahwa bangunan klenteng Kwang Sing Bio tidak hanya sebagai tempat ibadah saja, melainkan dapat dijadikan sebagi sumber belajar khususnya pelajaran sejarah di SMA.

Ketidak pedulian peserta didik terhadap mata pelajaran sejarah dikarenakan pelajaran sejarah berkesan membosankan dan terkesan banyak teori yang ada di dalamnya sedangkan prakteknya terlalu kurang, sehingga membuat banyak peserta didik yang kurang berminat dengan pelajaran sejarah.dengan mengunjungi tempattempat bersejarah yang ada disekitar lingkungan sekolah misalnya dengan mengunjungi tempat-tempat bersejarah yang ada di Kabupaten Tuban tepatnya di klenteng Kwang Sing Bio. Hal ini, bisa di jadikan langkah awal untuk mengembangkan rasa kepedulian dan ketertarikan untuk membuat peserta didik tertarik dengan mata pelajaran sejarah, karena pada kenyataanya bahwa mempelajari sejarah tidak harus hanya di 
dalam kelas saja melainkan dapat pula dipraktekkan dengan belajar di luar kelas.

Adapun aspek-aspek yang dimiliki oleh Klenteng Kwang Sing Bio sebagai sumber belajar sejarah di SMA, yaitu:

(1) Aspek Sejarah

Pemanfaatan aspek sejarah yang dimiliki oleh Klenteng Kwang Sing Bio dapat digunakan berdasarkan Silabus Mata Pelajaran Sejarah SMA $\mathrm{X}$ dan bahkan hingga di kelas XI yaitu yang membahas tentang warga Tionghoa di Indonesia khsusnya warga Tionghoa yang ada di Kabupaten Tuban. dengan mempelajari aspek sejarah dari bangunan Klenteng Kwang Sing dan sejarah Tionghoa yang ada di Tuban dengan mengaitkannya pada sumber belajar di sekolah (SMA/MA) di wilayah Kecamatan Tuban dalam sejarah Indonesia diharapkan semakin memupuk sikap menghargai dan menerima keberadaan etnis Tionghoa sebagai bagian dari bangsa Indonesia sebagaimana etnis lainnya. melalui bangunan Klenteng Kwang Sing Bio ini siswa-siswi juga diajarkan untuk menyadari betapa kayanya peradaban bangsa Indonesia sejak dulu yang secara sosial budaya banyak mempertontonkan kehidupan yang harmonis. Dengan semangat multikulturalisme yang tercipta di Kabupaten Tuban, siswa juga ditumbuhkan kesadaran persatuan, persaudaraan, dan solidaritasnya untuk mencegah terjadinya disintegrasi.Sehingga sikap toleransi yang tinggi di Indonesia khususnya masyarakat Tuban, dan dapat terrealisasikan isi dari Pancasila yang tidak hanya sebagai konsep yang tertulis namun juga sebagai pandangan hidup dari masyarakat Tuban.
(2) Aspek Bangunan

Bangunan klenteng Kwang Sing Bio dilihat dari aspek bagunan sangat mencirikan banguan berarsitektur Tiongkok. Orientasi klenteng ini dihadapkan ke laut lepas. Tempat ibadah ini dipersembahakan pada dewa "Guandi" atau dewa utama Kwang Sing Tee Koen. Pada altar disampingnya juga diletakkan patung kedua pengikutnya yaitu Guan Ping dan Zhou Chan. Keunikan yang dimiliki oleh klenteng Kwang Sing Bio merupakan salah satu ornamentik dengan ragam hias yang unik dan mengandung unsur historis.

Meskipun klenteng Kwang Sing Bio lebih di dominasi oleh ajaran Konghucu, akan tetapi di dalam Klenteng Kwang Sing Bio juga terdapat Vihara kecil yang khusus tempat ibadah bagi agama Budha. oleh karena itu, arsitektur dari banguna Klenteng Kwang Sing Bio sangat bisa dipergunakan sebagai sumber belajar sejarah di SMA, dan juga dapat dijadikan sebagai sumber belajar sejarah bagi para generasi muda yang ada di Kabupaten Tuban, sehingga memupuk sikap toleransi yang tinggi dan tidak adanya konflik yang berbau sara, yang kemudian menciptakan keharmoniasan bagi masyarakat di Kabupaten Tuban.

(3) Aspek Kerukunan antar Umat Beragama

Kerukunan antar umat beragama yang terdapat di Klenteng Kwang Sing Bio sangat tinggi. Tuban yang mayoritas beragama Islam tidak membuat warga keturunan Tionghoa merasa terdeskriminasi, akan tetapi menjadikan perbedaan tersebut sebagai kekuatan untuk terus memupuk kerukunan diantara masyarakat Tuban dan sekitarnya. 
Kerukunan yang diterapkan oleh warga Tuban sudah berlangsung selama bertahun-tahun lamanya.Kerukunan ini terlihat di dalam Klenteng Kwang Sing Bio yang mana tidak semua pegawai di klenteng Kwang Sing Bio penganut Tri Dharma, akan tetapi banyak dari masyarakat pribumi yang beragama Islam menjadi pegawai di dalam Klenteng Kwang Sing Bio, diantaranya sebagai Securrity, tukang masak, kuli bangunan, dan lain sebagainya. Selain itu kerukunan tidak hanya terjadi di dalam klenteng Kwang Sing Bio, akan tetapi juga terjadi di luar klenteng, contohnya beberapa tahun yang lalu saat Tuban terkena bencana bajir pihak klenteng memberikan sumbangan sembako kepada korban banjir . Hal ini dilakukan oleh pihak klenteng tidak lain hanya ingin meringankan beban dari masyarakat Tuban serta terus menumbuhkan sikap solidaritas sehingga tidak terjadi sinkritisme yang dapat merugikan kedua belah pihak dan memunculkan intoleransi dan radikalisme yang sekarang telah marak terjadi di Indonsia belakangan ini.Maka dari itu perlunya memupuk sikap toleransi sedini mungkin kepada para generasi muda agar mereka tidak mudah terpengaruh, dan keharmonisan tersebut terus berlangsung terus menerus di antara masyarakat Tuban dan sekitarnya.

Alasan MA Ash Shomadiyah belum Memanfaatkan Klenteng Kwang Sing Bio sebagai Sumber Belajar Sejarah

Sekolah MA Ash Shomadiyah adalah sekolah yang paling dekat dengan keberadaan dari bangunan Klenteng Kwang Sing Bio, dibandingkan dengan SMA-SMA yang lain.

Berdasarakan wawancara yang dilakukan penulis dengan Guru Mata Pelajaran Sejarah di MA Ash Shomadiyah yaitu ibu Siti Istiqomatin (35 tahun) pada tanggal 30 Mei 2017, beliau menyatakan bahwa, guru sejarah di MA Ash
Shomadiyah belum sepenuhnya memanfaatkan Klenteng Kwang Sinng Bio sebagai sumber belajar sejarah, dikarenakan ketidak tahuan guru sejarah di MA Ash Shomadiyh tentang sejarah pendirian Klenteng Kwang Sing Bio, sehingga membuat banyak guru sejarah di sekitar Klenteng tidak menggunakan Klenteng Kwang Sing Bio sebagai sumber belajar sejarah, begitu pula dengan MA Ash Shomadiyah, akan tetapi mesipun tidak dipergunakan sebagai sumber belajar sejarah akan tetapi ibu Istianah selaku guru sejarah di MA Ash Shomadiyah telah berusaha memperkenalkan keberadaan Klenteng Kwang Sing Bio meskipun tidak secara spesifik diterapkan pada mata pelajaran sejarah akan teapi lebih pada mata pelajaran yang berkaitan dengan IPS yaitu mata pelajaran PPKN, Sosiologi dan Sejarah. Sebenarnya terdapat aspek-aspek penting yang dimiliki klenteng Kwang Sing Bio yang dapat dipergunakan sebagai sumber belajar sejarah bagi MA Ash Shomadiyah seperti adanya Vihara di dalam klenteng Kwang Sing Bio yang mana adalah bangunan tempat ibadah bagi agama Budha, yang nanti dapat dikaitkan pada materi bukti-bukti peninggalan pengaruh Hindu-Budha yang ada di dalam Klenteng Kwang Sing Bio. Hal ini, dimaksudkan untuk membantu pemahaman siswa terhadap nilai-nilai kesejarahan serta dapat meningkatkan minat siswa dalam belajar sejarah. Melalui pengembangan dan penempatan bangunan klenteng Kwang Sing Bio sebagai sumber belajar terlepas apakah materi tersebut dikemas dalam mata pelajaran sejarah atau pun mata pelajaran yang lain.

\section{PENUTUP}

\section{Kesimpulan}

Klenteng Kwang Sing Bio didirikan pada tahun 1742 yaitu sekitar 275 tahun yang lalu.klentengKwang SingBioadalah 
tempat suci bagi umat Tri Dharma, yaitu Klenteng yang diperuntukan untuk tiga agama, yaitu Konghucu (Konfusianisme), Buddha (Buddhisme), dan Tao (Taoisme).

Klenteng Kwang Sing Bio dalam perannya sebagai tempat suci bagi umat Tri Dharma, memilik struktur tersendiri yang menbedakan dengan tempat ibadah lain. Klenteng Kwang Sing Bio tidak mendasarkan struktur bangunan berdasarkan pada pembagian halaman seperti pada pembuatan Pura yang ada di Bali, akan tetapi disesuaikan berdasarkan tempat yang ditempatinya, dan gaya arsitekturnya tetap mencirikan bangunan yang bergaya Tiongkok

Dalam perannya sebagai tempat suci bagi umat Tri Dharma, Klenteng Kwang Sing Bio memiliki beberapa fungsi, baik itu fungsi religi maupun fungsi nonreligi.

Klenteng Kwang Sing Bio adalah klenteng yang memiliki sejarah yang penting bagi warga Tionghoa yang ada di Kabupaten Tuban, dan klenteng Kwang Sing Bio memiliki potensi sebagai sumber belajar sejarah di SMA, khususnya di MA Ash Shomadiyah. Alasan mengapa guru kurang memanfaatkan Klenteng Kwang Sing Bio sebagai sumber belajar sejarah disebabkan karena ketidak tahuan guru tentang sejarah Klenteng Kwang Sing secara mendalam, dan kurangnya perhatian dari pemerintah daerah tentang potensi dari Klenteng Kwang Sing dalam memanfaatkan bangunan klenteng di dunia pendidikan. Sehingga sampai klenteng Kwang Sing Bio belum dimanfaatkan sebagai sumber belajar sejarah.

\section{Saran}

Berdasarkan hasil penelitian di atas, maka dapat disampaikan beberapa saran, yakni:

1. Bagi peneliti, penelitian di Klenteng Kwang Sing Bio ini, masih banyak hal yang menarik yang belum diteliti karena keterbatasan peneliti, maka dari itu diharpakan kepada peneliti lain untuk meneliti lebih mendalam mengenai aspek-aspek lain dari Klenteng Kwang Sing Bio dan daya tari dari Klenteng Kwang Sing Bio.

2. Bagi pemerintah setempat, demi menjaga eksistensi dari Klenteng Kwang Sing Bio perlunya perhatian yang lebih dalam rangka menjaga dan melestarikan peninggalan budaya, baik dari pengurus Klenteng Kwang Sing Bio dan seluruh umat Tri Dharma maupun semua keturunan Tionghoa, terutama kepada pemerintah setempat agar terus memperhatikan keberadaan dari bangunan Klenteng Kwang Sig Bio sehingga keberadaannya tetap terus menjadi salah satu icon di Kabupaten Tuban.

3. Kepada para guru dan pengajar di Kabupaten Tuban, diharapkan Klenteng Kwang Sing Bio dapat di fungsikan sebagai salah satu sumber belajar bagi siswa-siswa di Kabupaten Tuban agar nantinya para pengajar atau guru dapat mengembangkan media pembelajaran yang interaktif bagi para siswa-siswi, agar pelajaran sejarah tidak terus dipandang sebelah mata karena selalu bersifat monoton, dan juga menjadikan pelajaran sejarah agar lebih bervariasi.

4. Bagi masyarakat kelurahan Karangsari agar terus ikut menjaga dan melestarikan keberadaan Klenteng Kwang Sing Bio agar keberadaanya tetap terpelihara, sehingga terus tercipta toleransi yang tinggi, dan menjadikan kelnteng Kwang Sing Bio sebagai tolok ukur untuk terus hidup rukun 
sesama warga kelurahan Karangsari meskipun berbeda agama, yang akhirnya melahirka kedamian dan kesejateraan.

\section{DAFTAR PUSTAKA}

\section{Sumber Buku:}

Jun, Wang Xiang. 2010. Orang-orang

China Yang Mempengaruhi

Kemerdekaan Indonesia.

Yogyakarta: Pustaka Solomon

Xiang

Sukmandinata, Nata Syaodih. 2009. Metode Penelitian Pendidikan.

Bandung: PT. Remaja

Rosdakarya

Suwartono. 2014. Dasar-dasar Metodologi

Penelitian. Yogyakarta:

Penerbit Andi

Yoest. 2008. Riwayat Klenteng, Vihara,

Lithang Jakarta dan

Banteng. Jakarta: PT.

Buana Ilmu Populer

\section{Sumber Internet:}

https://tubankab.bps.go.id/linkTabelStatis/v iew/id/214, diakses tanggal 9 maret 2017, pukul 11.30 Wita. 